ISSN 1980-5098 @® DOI: http://dx.doi.org/10.5902/1980509832082

\title{
EFEITO DA DESFOLHA ARTIFICIAL NO CRESCIMENTO DO VIMEIRO
}

\author{
EFFECT OF ARTIFICIAL DEFOLIATION ON THE GROWTH OF WILLOW
}

\author{
Tássio Dresch Rech ${ }^{1}$ Justina Inês Anselmini ${ }^{2}$ Luciene Martins Moreira ${ }^{3}$ Sandra Regina Cabel ${ }^{3}$ \\ Lizane Lúcia de Souza ${ }^{4}$ Cícero Deschamps ${ }^{5}$
}

\begin{abstract}
RESUMO
O vimeiro (Salix x rubens) é uma planta lenhosa, de origem europeia, usada no Brasil para artesanato e movelaria. A cultura do vimeiro é eventualmente atacada por lagartas e formigas que causam a perda de área foliar. Este estudo objetivou avaliar o efeito de níveis de desfolha no crescimento do vimeiro. $\mathrm{O}$ experimento foi conduzido em uma estufa. As plantas foram mantidas em vasos com capacidade de 8 litros sob nebulização intermitente, de agosto a dezembro de 2004. O delineamento foi em blocos casualizados, com cinco repetições e quatro tratamentos $(0,25,50$ e $75 \%$ de desfolha do número total de folhas) avaliados quanto ao teor de açúcares redutores, área foliar e massa fresca e seca, caules e folhas. O desfolhamento $(\%)$ reduziu a massa $\left(\mathrm{MH}=-0,1067 \mathrm{x}+19,03, \mathrm{R}^{2}=0,98\right)$ e o diâmetro final das hastes $(\mathrm{DH}=-0,0114 \mathrm{x}+$ $\left.5,172, \mathrm{R}^{2}=0,98\right)$, assim como a massa foliar $(\mathrm{MF}=-0,1028 \mathrm{x}+13,892 ; \mathrm{R} 2=0,99)$ e o número de folhas $\left(\mathrm{NF}=-0,2545 \mathrm{x}+36,87, \mathrm{R}^{2} \sim 0,998\right)$. A partição de assimilados foi alterada em favor da restauração da área foliar.
\end{abstract}

Palavras-chave: Salix x rubens; fitomassa; partição de assimilados.

\begin{abstract}
The willow (Salix x rubens) is a woody plant of European origin, used in Brazil for handicrafts and furniture. This culture is eventually attacked by caterpillars and ants, which cause the loss of the leaf area. This study aimed to evaluate the effect of levels of defoliation on the growth of willow. The experiment was conducted in a greenhouse. The plants were kept in pots with a capacity of 8 liters under intermittent mist, from August to December 2004. The design was a randomized block with five replications and four treatments $(0,25,50$ and $75 \%$ defoliation of the total number of leaves) were evaluated for reducing sugar content, leaf area and fresh and dry stems and leaves. The defoliation reduced the final weight (WR $=-0,1067 x+19,03$, $\left.\mathrm{R}^{2}=0,98\right)$ and diameter of the rods $\left(\mathrm{DM}=-0,0114 \mathrm{x}+5,172, \mathrm{R}^{2}=0,98\right)$, and the leaf weight $(\mathrm{MF}=-0,1028 \mathrm{x}$ $+13,892 ; \mathrm{R} 2=0,99)$ and leaf number $\left(\mathrm{NF}=-0,2545 \mathrm{x}+36,87, \mathrm{R}^{2} \sim 0,998\right)$. The partition of assimilates has been modified in favor of the restoration of leaf area.
\end{abstract}

Keywords: Salix x rubens; phytomass; assimilate partitioning.

\section{INTRODUÇÃO}

O vimeiro (Salix $x$ rubens) é uma planta lenhosa, de origem europeia, introduzida durante a

1 Engenheiro Agrônomo, Dr., Pesquisador da Empresa de Pesquisa Agropecuária e Extensão Rural de Santa Catarina, Rua João José Godinho, s/n, Caixa Postal 181, CEP 88502-970, Lages (SC), Brasil. tassior@epagri. sc.gov.br

2 Bióloga, Dra ., Departamento de Fitotecnia e Fitossanitarismo, Universidade Federal do Paraná, Rua dos Funcionários, 1540, CEP 80035-050, Curitiba (PR), Brasil. justinaines@pop.com.br

3 Engenheira Agrônoma, Dr ${ }^{\mathrm{a}}$., Professora da Pontifícia Universidade Católica do Paraná, Rua Imaculada Conceição, 1155, CEP 80215-901, Curitiba (PR), Brasil.1mmoreira@terra.com.br / sandrareginacabel@gmail.com

4 Engenheira Agrônoma, MSc., SQN 216 Bloco C apto 403, Asa Norte, CEP 70875-030, Brasília (DF), Brasil. lizanesouza@gmail.com

5 Engenheiro Agrônomo, Dr., Professor do Departamento de Fitotecnia e Fitossanitarismo, Universidade Federal do Paraná, Rua dos Funcionários, 1540, CEP 80035-050, Curitiba (PR), Brasil. cicero@ufpr.br

Recebido para publicação em 10/02/2011 e aceito em 2/05/2017

Ci. Fl., v. 28, n. 2, abr .- jun., 2018 
década de 1930 pelos imigrantes italianos que utilizavam suas hastes para prender ramos de parreiras (EMPRESA DE PESQUISA AGROPECUÁRIA E EXTENSÃO RURAL DE SANTA CATARINA, 2006). Recentemente, além do uso tradicional, o vime é utilizado no Brasil para artesanato e movelaria. Na região do rio Canoas (SC) são cultivadas exclusivamente plantas femininas de Salix x rubens (Schrank), que é um híbrido interespecífico de Salix alba e Salix fragilis. No entanto, esta espécie é pouco utilizada nos países da Europa (EMPRESA DE PESQUISA AGROPECUÁRIA E EXTENSÃO RURAL DE SANTA CATARINA, 2006).

A cultura é adaptada aos estados do sul do Brasil, em regiões de clima temperado, normalmente em áreas ribeirinhas, com boa umidade no solo durante todo o ano. O manejo se caracteriza por cortes anuais da rebrota, que para fins de artesanato deve constituir-se de ramos retos, delgados, com diâmetros uniformes, flexíveis e sem marcas (SILVA, 1999). Esta cultura é eventualmente atacada por lagartas e formigas que causam perda de área foliar, podendo acarretar aumento na ramificação lateral, o que é indesejável para o artesanato (TAGLIARI, 1998).

Alguns fatores devem ser considerados na avaliação das perdas de produção devido ao desfolhamento. Entre eles, pode-se citar: a capacidade de rebrota da espécie vegetal, ciclo da cultura, variedade, densidade de plantas, irrigação da cultura, estágio de desenvolvimento da planta, níveis de desfolha, parte da planta afetada pela desfolha, a própria metodologia de desfolhamento artificial, interação da desfolha com outros agentes fitopatogênicos, hábito alimentar do inseto que causa dano por desfolha (LAMP; BRITT, 1981; CHEN; KOLB; CLANCY, 2002; ERBILGIN et al., 2014).

Os açúcares redutores fazem parte dos açúcares não estruturais cujos teores são sensíveis variações ambientais e injúrias sofridas pelas plantas. Estes açúcares têm sido utilizados para avaliar as respostas das plantas às condições de estresse, como o deficit hídrico, frio e desfolha, por serem produtos, tanto das rotas de síntese a partir da fotossíntese, quanto da mobilização de reservas de amido e alterarem tensão osmótica das células (LOESCHER; MCCAMANT; KELLER, 1990; CANDOLFI-VASCONCELOS; KOBLET 1991; KOSOLA et al., 2001; BENNETT et al., 2005; SOUZA et al., 2013).

Este trabalho objetivou avaliar o efeito de níveis de desfolha artificial no crescimento e na concentração de açúcares redutores.

\section{MATERIAL E MÉTODOS}

O experimento foi conduzido em condições parcialmente controladas de casa de vegetação $\left( \pm 25^{\circ} \mathrm{C}\right)$, $25^{\circ} 24^{\prime} 47^{\prime \prime} \mathrm{S} / 49^{\circ} 14^{\prime} 53^{\prime \prime} \mathrm{O}$, durante os meses de julho a novembro, com iluminação natural e nebulização intermitente de 2 min a cada hora.

Estacas de Salix x rubens, coletadas em Lages-SC, $25^{\circ} 24^{\prime} 47^{\prime \prime} \mathrm{S} / 49^{\circ} 14^{\prime} 53^{\prime \prime}$ foram cultivadas em sacos plásticos de $2 \mathrm{~L}$ até os 60 dias após o início da brotação conduzida para obtenção de mudas com dois ramos cada. Para o cultivo foi utilizado solo franco-arenoso corrigido para $\mathrm{pH}$ 6,5 com calcário dolomítico (SOCIEDADE BRASILEIRA DE CIÊNCIA DO SOLO, 1995), posteriormente, as mudas foram transferidas para vasos plásticos de $8 \mathrm{~L}$ contendo o mesmo solo adubado com $1,5 \mathrm{~L}$ de casca de vime e 1,5 g de fertilizante mineral 9-10-10. As plantas permaneceram em nebulização intermitente durante toda a condução do experimento.

A partir da terceira semana após a transferência para os vasos foram realizadas medições semanais de comprimento da haste principal (da inserção na estaca até a base da última folha expandida), diâmetro dos ramos (entre as inserções da segunda e terceira folha) e contagem do número de folhas na quarta e quinta semanas, sendo que na sexta semana ocorreu a desfolha.

O delineamento foi em blocos ao acaso, em um total de cinco, com três plantas (vasos) por unidade experimental e quatro tratamentos, que consistiram na remoção sistemática de $0,1,2$ ou 3 folhas a cada sequência de 4 folhas, correspondendo a 0,25, 50 e 75\% de desfolha. As folhas foram removidas por corte dos pecíolos com tesoura.

Após a desfolha, as medições de altura, diâmetro dos ramos e contagem do número de folhas ocorreram por três semanas, e ao final, todas as folhas foram coletadas e separadas em folhas maduras e jovens para determinação da área foliar, do peso fresco e seco, dos teores de açúcares redutores e 
proteínas totais.

A separação de folhas jovens e maduras considerou o incremento do tamanho das folhas que se observa nos ramos de vimeiro da extremidade superior do ramo seguido de estabilização deste e redução das folhas próximas à base do ramo. As folhas da extremidade superior do ramo com tamanho inferior ao par de folhas subsequente foram consideradas jovens. A separação em folhas jovens e maduras foi considerada apenas para as análises de teores de proteína e açúcares.

$\mathrm{O}$ incremento de comprimento e de diâmetro das hastes e do número de folhas foi calculado pela diferença entre a medição/contagem no momento da aplicação dos tratamentos e no final da condução do mesmo.

Foi calculada ainda a taxa de geração de novas folhas (Tnf) como resultado da divisão do número de folhas final (NFF) subtraído do número de folhas remanescentes imediatamente após a desfolha (Nfr) e depois, dividido por esse mesmo número:

$$
T n f=\frac{N F F-N r f}{N r f} \text {. }
$$

A massa seca de folhas e hastes foi obtida após secagem em estufa na temperatura de $65^{\circ} \mathrm{C}$ por 72 horas. Os teores de açúcares redutores foram determinados pelo método do DNS (MILLER, 1959) por espectrofotometria, utilizando-se 1 grama de folhas. Para a determinação de proteína nos tecidos foliares foi utilizado o método de Bradford (BRADFORD, 1976), em que $1 \mathrm{~g}$ de folhas frescas, na forma de discos foliares com área de $0,7854 \mathrm{~cm}^{2}$ foram lavados e secos sendo, posteriormente, macerados em $10 \mathrm{~mL}$ de solução tampão fosfato $0,2 \mathrm{M} \mathrm{pH} 7,5$. Os discos foliares foram retirados do centro das folhas amostradas. $\mathrm{O}$ extrato obtido foi, em seguida, filtrado e centrifugado por 10 minutos, a $20.000 \mathrm{x} \mathrm{g}$, a $4^{\circ} \mathrm{C}$. Após a centrifugação foi retirada uma alíquota $40 \mu \mathrm{L}$ do sobrenadante e transferida para um tubo de ensaio, sendo adicionados $460 \mu \mathrm{L}$ de tampão fosfato $0,2 \mathrm{M} \mathrm{pH} 7,5$, e $1000 \mu \mathrm{L}$ do reagente de Bradford (1:4, v/v). A leitura das absorbâncias foi obtida em espectrofotômetro Shymadzu UV-1601 no comprimento de onda de $630 \mathrm{~nm}$. As concentrações de proteínas foram calculadas por meio de curva padrão de soro albumina bovina (BSA), de acordo com a metodologia de Kruger (1994).

Os dados obtidos foram submetidos à análise de variância, ANOVA (teste F) e, quando significativo o efeito de tratamento, regressão linear para as doses de desfolha.

\section{RESULTADOS E DISCUSSÃO}

A desfolha resultou em redução: da massa e do número final de folhas (Figura 1A); do incremento de comprimento das hastes (Figura 1B); no diâmetro final das hastes e de seu incremento (Figura 1C); e do número final das hastes (Figura 1D). Coyle et al. (2002) observaram reduções no incremento de diâmetro e altura de plantas de Populus spp que sofreram ataque de coleópteros fitófagos por três anos consecutivos em relação às populações que foram protegidas por inseticidas. Da mesma forma, Agrawal, Kosola e Parry (2002) constataram que a desfolha tem efeito negativo sobre o crescimento e a produtividade das plantas Populus x euramericana Dode (Guinier), causando maior mortalidade (10\%) nas parcelas que sofreram desfolha. Cedervind (2003) observou que a intensidade de desfolha de Pinus silvestris L. por lagartas e besouros causava perdas proporcionais de volume e altura.

Reduções na produção de massa seca promovidas pela desfolha também foram observadas por Islam (2014), apesar de ter constatado aumento na taxa de fotossíntese e de condutividade estomática nas plantas desfolhadas. Filippeto (2008) observou menores diâmetros de plantas de videira submetidas à desfolha de 50 e $75 \%$, enquanto as plantas com desfolha de $25 \%$ se mostravam semelhantes às não desfolhadas.

Entretanto, o incremento no número de folhas foi favorecido pela desfolha (Figura 1D), o que indica direcionamento compensatório do crescimento nas plantas desfolhadas, no sentido de recomposição da superfície fotossintetizante, pois o incremento no número de folhas foi maior nos tratamentos com desfolha mais intensa. A ausência de diferenças significativas no comprimento final das hastes entres os tratamentos pode ser resultado de um efeito de diluição pelo comprimento inicial, semelhante em todos os tratamentos, sobre o valor do comprimento final. 

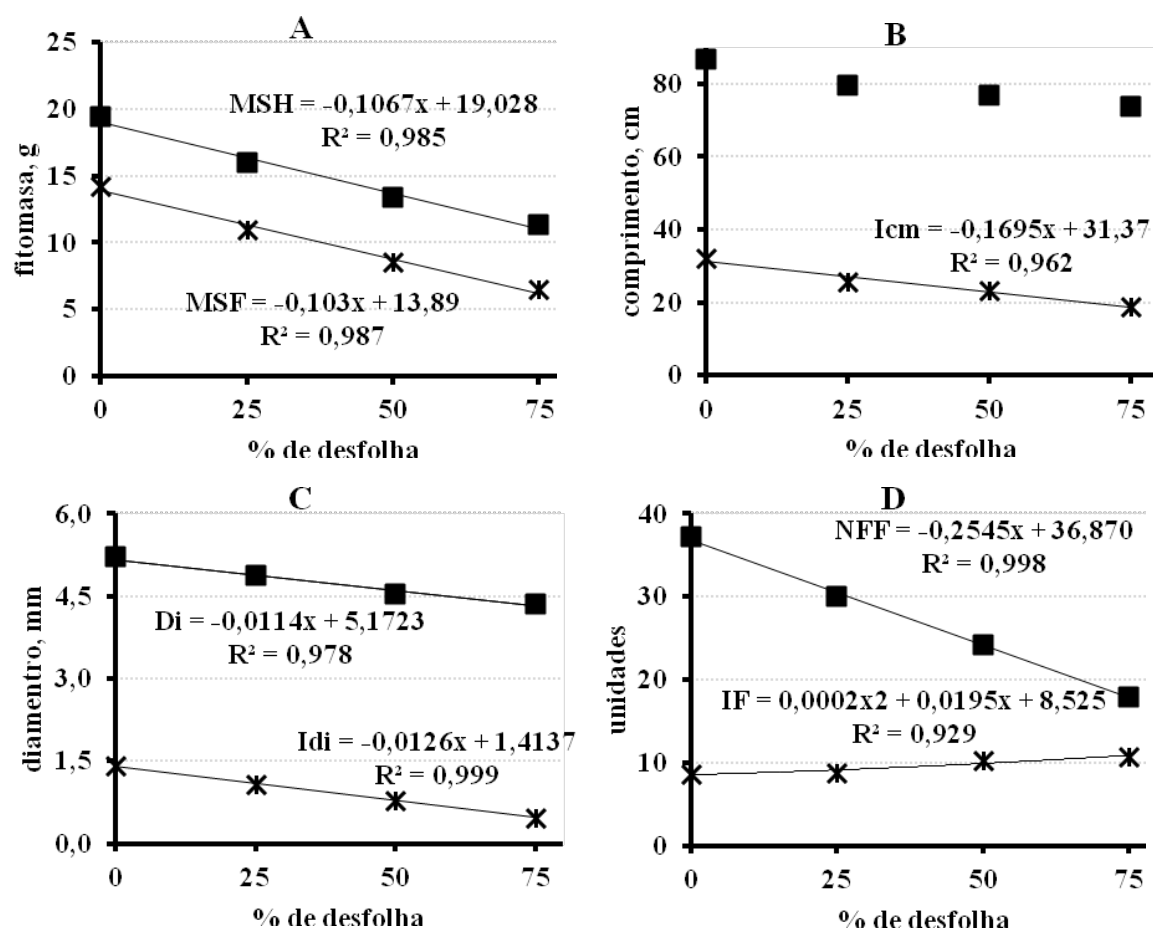

FIGURA 1: Efeitos da desfolha artificial do vimeiro em vasos (Curitiba-PR): A - Fitomassa seca de hastes (MSH, -), e folhas (MSF, $\boldsymbol{*}$ ); B - comprimento final (-) e incremento do comprimento das hastes (Icm, ); $\mathrm{C}$ - diâmetro final $(\mathrm{Di}, \mathbf{\square})$ e incremento de diâmetro das hastes (Idi, $\boldsymbol{*})$; D - número de final de folhas $(\mathrm{NFF}, \boldsymbol{\square})$ e incremento do número de folhas $(\mathrm{IF}, \boldsymbol{*}) .{ }^{*}$ Coeficientes lineares das equações de regreșão significativos a $5 \%$.

FIGURE 1: Effects of artificial defoliation of willow in pots (Curitiba, PR state, Brazil): A - Biomass dry stems $(\mathrm{MSH}, \boldsymbol{\square})$ and leaves (MSF, $\boldsymbol{*})$, B - length (-) and increase in length of stems (Icm, $\boldsymbol{*}$ ); C - Final diameter $(\mathrm{Di}, \mathbf{\square})$ and stem diameter increment (Idi, X); D - final leaf number (FLN, $\mathbf{\square})$ and increase the number of leaves $(\mathrm{IF}, \boldsymbol{*}) . *$ Coefficient of linear regression equations significant at $5 \%$.

A alteração na distribuição de fotoassimilados entre as estruturas das plantas fica ainda mais caracterizada quando se observa a taxa de formação de novas folhas por folha remanescente e a taxa de crescimento de ramo por folha remanescente (Figura 2). Enquanto no tratamento sem desfolha, cada folha remanescente deu origem a 0,3 novas folhas e pouco mais de $1 \mathrm{~cm}$ de crescimento de ramos, no tratamento com desfolha de $75 \%$ essas relações foram de 1,5 novas folhas e mais de $2,5 \mathrm{~cm}$ de crescimento de ramos por folha. Isto caracteriza uma alocação prioritária do carbono fixado na recomposição da área foliar e uma provável mobilização de reversas. Volin, Kruger e Lindroth (2002) trabalhando com desfolha de 50\% em plátano verificaram que este tratamento não afetou a biomassa final de plântulas, mas ocorreu uma realocação desta no incremento foliar.

O incremento na taxa de formação de folhas e mesmo no maior número de folhas formadas nos tratamentos com maior desfolha foi suficiente apenas para aproximar os valores de área foliar formada, mas não para repor as perdas sofridas (Figura 2). Parte do incremento da eficiência por unidade de folha pode ser explicado pelo incremento dos teores de proteínas nas folhas maduras (Figura 2 D), possivelmente resultante de um aumento dos teores de clorofila e demais organelas e substâncias associadas à fotossíntese. 

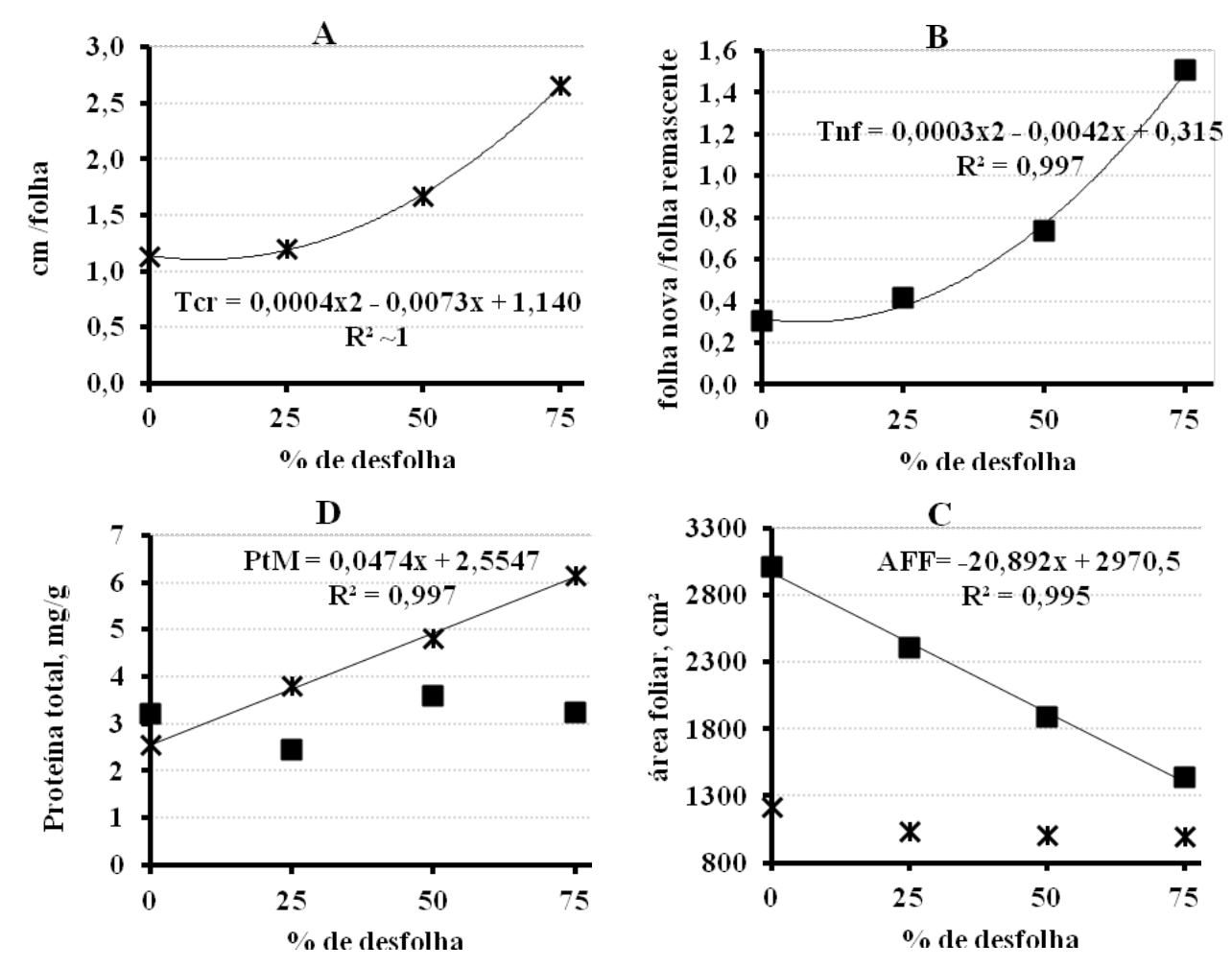

FIGURA 2: Efeitos da desfolha artificial do vimeiro em vasos (Curitiba-PR): A - Taxa de crescimento de ramo por unidade de folha remanescente $(\mathrm{Tcr}, \boldsymbol{*})$; B - Taxa de novas folhas por folha remanescente (Tnf, - I); $\mathrm{C}$ - área foliar final $(\mathrm{AFF}, \boldsymbol{\Xi})$ e incremento da área foliar $(\boldsymbol{*})$; D - teor de proteínas das folhas maduras $(\operatorname{PtM}, \boldsymbol{*})$ e novas $(\boldsymbol{\square})$.

FIGURE 2: Effects of artificial defoliation of willow in pots (Curitiba, PR state, Brazil): A - rate of branch growth per unit leaf biomass (Tcr,* ); B - Rates of new leaf by leaf remaining (Tnf, $\mathbf{m})$; C - final leaf area $($ FFA, $\boldsymbol{\square})$ and increased leaf area $(\boldsymbol{*})$; D - protein content of mature leaves (PTM, $\boldsymbol{*})$ and new ones($(\boldsymbol{\square})$.

Finalmente, a desfolha não influenciou de forma consistente os teores de açúcares redutores, sendo observada apenas diferença entre as folhas maduras, $58 \mathrm{~g} \mathrm{~g}^{-1}$ e folhas novas, $47 \mathrm{~g} \mathrm{~g} \mathrm{~g}^{-1}$. De forma semelhante, Mandre, Tullus e Kloseiko (2002) encontraram baixa correlação entre o comprimento dos ramos em diferentes camadas da copa de Pinus sylvestris L. e os teores de açúcares solúveis, porém, uma alta correlação com amido, no período de verão. No outono, quando o crescimento das árvores estabilizou, a alocação de açúcares solúveis foi correlacionada com o comprimento dos ramos. Porém, Hudgeons et al. (2007) observaram que o ataque de Diorhabda elongata (Brulle'), um besouro que causa desfolha em Tamarix L, uma espécie arbórea invasora de ecossistemas ripários nos Estados Unidos, reduziu os teores de açúcares não estruturais e o rebrote da planta. Loescher, McCamant e Keller (1990) destacaram que os açúcares redutores, frutose e glicose, normalmente aparecem em concentrações menores que a sacarose na parte aérea de plantas lenhosas. Mas, em plantas de carvalho, a desfolha causou a redução dos teores de amido e sacarose nas raízes e incremento da concentração de frutose e glicose na região cambial da casca (WARGO, 1996). Assim, a seleção do tecido avaliado pode não ter sido a mais adequada para avaliação da mobilização e alteração de síntese de carboidratos promovida pela desfolha no presente trabalho.

Körner (2003) afirmou que o ganho de biomassa pode ser separado em dois grupos de compostos de $\mathrm{C}$, um grupo com compostos formado apenas por $\mathrm{C}, \mathrm{H}$ e $\mathrm{O}$ (carboidratos, ácidos orgânicos, lipídeos, álcool-açúcar, fenóis, polímeros isoprenos, terpenoides, etc.) e outro formado não exclusivamente por $\mathrm{C}, \mathrm{H}$ e $\mathrm{O}$ (enzimas, proteínas, peptídeos, alguns compostos secundários, material de parede celular e organelas celulares). Uma vez que neste trabalho determinou-se apenas um pequeno grupo dos carboidratos não estruturais, isto pode não representar o efeito da desfolha na partição de açúcares ou representar um momento muito específico do metabolismo do vimeiro. 
Um aspecto a ser considerado foi observado por Chen, Kolb e Clancy (2002), trabalhando com desfolha de Pseudotsuga menziesii (Mirb). Aqueles autores concluíram que a desfolha artificial pode genericamente simular efeito semelhante ao provocado pela lagarta das gemas (Choristoneura occidentalis Freeman) na fitomassa total, mas os dois tipos de desfolha têm efeitos diferentes na alocação de biomassa. A desfolha artificial decresce o peso das plantas, a taxa de crescimento em altura e a relação parte aérea-raiz mais que o ataque de lagartas, enquanto a desfolha pelas lagartas afeta mais o crescimento em diâmetro das hastes. Estes resultados sugerem cuidado na extrapolação dos efeitos da desfolha artificial para o ataque de lagartas do vimeiro. Em condição de ataque de lagarta, não necessariamente as folhas terão a sua recomposição de forma semelhante à observada na desfolha artificial.

\section{CONCLUSÕES}

A desfolha artificial atua direta e negativamente sobre o crescimento de plantas de vimeiro. Porém, a alteração na partição de assimilados resulta em taxas equivalentes de formação de novas folhas, independentemente da intensidade de desfolha.

\section{REFERÊNCIAS}

AGRAWAL, A. A.; KOSOLA, K. R.; PARRY, D. Gypsy moth defoliation and N fertilization affect hybrid poplar regeneration following coppicing. Canadian Journal of Forest Research, New Westminster, v. 32, p. 1491-1495, 2002.

BENNETT J. et al. Influence of defoliation on overwintering carbohydrate reserves, return bloom, and yield of mature Chardonnay grapevines. American Journal of Enology and Viticulture, Davis, v. 56, n. 4, p. 386-393, 2005.

BRADFORD, M. M. Rapid and sensitive method for quantification of microgram quantities of protein utilizing principle of protein dye binding. Analytical Biochemestry, New York, v. 72, p. 248-254, 1976.

CANDOLFI-VASCONCELOS, M. C.; KOBLET, W. Influences of partial defoliation on gas exchange parameters and chlorophyll content of field-grown grapevines: mechanisms and limitations of the compensation capacity. Vitis, Siebeldingen, v. 30, p. 129-141, 1991.

CEDERVIND, J. Impact of Pine Looper Defoliation in Scots Pine. 2003. 44 f. Tese (Doutorado) - Swedish University of Agricultural Sciences, Uppsala, 2003.

CHEN, Z.; KOLB, T. E.; CLANCY, K. M. Effects of artificial and western spruce budworm (Lepidoptera: Tortricidae) defoliation on growth and biomass allocation of douglas-fir seedlings, Journal of Economic Entomology, Lanham, v. 95, n. 3, p. 587-594, 2002.

COYLE, D. R. et al. Cottonwood leaf beetle (Coleoptera: Chrysomelidae) defoliation impact on Popolus growth and above-ground volume in a short-rotation woody crop plantation. Agricultural and Forest Entomology, Oxford, v. 4, p. 293-300, 2002.

EMPRESA DE PESQUISA AGROPECUÁRIA E EXTENSÃO RURAL DE SANTA CATARINA. Sistema para a produção de vime. Florianópolis: Epagri, 2006. 40 p. (Epagri - Sistemas de Produção, n. 44).

ERBILGIN, N. et al. Resource availability and repeated defoliation mediate compensatory growth in trembling aspen (Populus tremuloides) seedlings. PeerJ, San Diego, v. 2, p. e491, 2014. Disponível em: $<$ https://www.ncbi.nlm.nih.gov/pmc/articles/PMC4106189/>. Acesso em: 20 mar. 2017. doi: 10.7717/ peerj.491.

FILIPPETO, L. Influência da desfolha natural sobre o comportamento vegetativo e qualidade de produção da safra seguinte da uva Cabernet Sauvignon. 2008. 55 f. Monografia (Graduação em Enologia) - Centro Federal de Educação Tecnológica de Bento Gonçalves, Bento Gonçalves, 2008.

HUDGEONS, J. L. et al. Defoliation by introduced Diorhabda elongata leaf beetles (Coleoptera: Chrysomelidae) reduces carbohydrate reserves and regrowth of Tamarix (Tamaricaceae). Biological Control, Lexington, v. 43, n. 2, p. 213-221, 2007.

ISLAM, M. T. Effects of defoliation on photosynthesis, dry matter production and yield in soybean. Bangladesh Journal of Botanic, Bangladesh v. 43, n. 3, p. 261-265, 2014.

KÖRNER, C. Cottonwood leaf beetle (Coleoptera: Chrysomelidae) defoliation impact on Popolus growth

Ci. Fl., v. 28, n. 2, abr .- jun., 2018 
and aboveground volume in a short-rotation woody crop plantation. Journal of Ecology, London, v. 91, p. 4-17, 2003.

KOSOLA, K.R. et al. Repeated insect defoliation effects on growth, nitrogen acquisition, carbohydrates, and root demography of poplars. Oecologia, Heidelberg, v. 129, p. 65-74, 2001.

KRUGER N.J. The Bradford Method for Protein Quantitation. In: Walker J.M. (eds) Basic Protein and Peptide Protocols. Methods in Molecular Biology: Humana Press, v. 32, p. 9-15, 1994

LAMP, W. O.; BRITT. N. W. The resource partitioning by two species of stream mayflies (Ephemeroptera: Heptageniidae). Great Lakes Entomologist, Michigan, v. 14, n. 3, p. 151-158, 1981.

LOESCHER, H.; MCCAMANT, T.; KELLER, J. D. Carbohydrate reserves, translocation, and storage in woody plant roots. Hortscience, Wayne, v. 25, n. 3, 1990.

MANDRE, M.; TULLUS, H.; KLOSEIKO, J. Partitioning of Carbohydrates and Biomass in Scots Pine. Zeitschrift für Naturforschung, Mainz, v. 57, p. 296-302, 2002.

MILLER, G. L. Use of dinitrosalicylic acid reagent for determination of reducing sugar. Analytical chemistry, Washington, v. 31, n. 3, p. 426-428, 1959.

SILVA, G. O vime - cultivo e arte. Globo Rural, Rio de Janeiro, v. 169, p. 48-52, nov. 1999.

SOCIEDADE BRASILEIRA DE CIÊNCIA DO SOLO. Recomendação de adubação e calagem para os estados do Rio Grande do Sul e de Santa Catarina. 3.ed. Passo Fundo, RS: SBCS/Núcleo Regional Sul; Comissão de Fertilidade do Solo - RS/SC, 1994. 224p.

SOUZA, E. R. et al. Variação de carboidratos em folhas da videira 'Itália' submetida a diferentes de níveis de desfolhas. Revista Brasileira de Ciências Agrárias, Recife, v. 8, n. 4, p. 535-539, 2013. Disponível em: $<$ http://ainfo.cnptia.embrapa.br/digital/bitstream/item/96541/1/Barbara.pdf $>$. Acesso em: 02 ago. 2016.

TAGLIARI, P. O vime. Revista Agropecuária Catarinense, Florianópolis, v. 4, p. 45-47, 1998.

VOLIN, J. C.; KRUGER, E. L.; LINDROTH, R. L. Responses of deciduous broadleaf trees to defoliation in a $\mathrm{CO}_{2}$ enriched atmosphere. Tree Physiology, Victoria, v. 22, p. 435-448, 2002.

WARGO, P. M. Consequences of environmental stress on oak: predisposition to pathogens. Annales des Sciences Forestières, Versailles, v. 53, n. 2-3, p. 359-368, 1996. 